\title{
Preparation and properties of pearl powder/polypropylene composites and their biocompatibility
}

\author{
Yanhui Deng, Guang Li*, Weili Song and Jianming Jiang \\ State Key Laboratory for Modification of Chemical Fibers and Polymer Materials, College of \\ Material Science and Engineering, Donghua University, Shanghai, 201620, China
}

\begin{abstract}
To improve the biocompatibility of PP monofilaments used for pelvic reconstruction mesh, natural pearl powders were introduced as fillers in the preparation of modified PP monofilaments. The mechanical properties the modified PP monofilaments were analyzed, followed by characterization by scanning electron microscopy (SEM). Then, the biocompatibilities of these samples were investigated by MTT assay. The results revealed that the tensile strength and elongation of the as-prepared PP monofilaments can satisfy the requirement. According to the SEM images, masses of pearl powder were observed on the surface of monofilaments, which may favor the cell growth. The MTT results and the confocal microscopical images indicated that the presence of pearl powder in PP monofilaments led to improved proliferation and growth of L929 and PIEC cells under the same conditions, suggesting that PP monofilaments modified by pearl powders have a great potential in the applications of pelvic reconstruction.
\end{abstract}

Keywords: PP monofilament, pearl powder, mechanical property, biocompatibility, pelvic

\section{Introduction}

According to statistics, over $50 \%$ of the female aged over 50 are suffering from pelvic disturbances, which make their life depressed [1]. Currently, the most commonly used treatment for pelvic disturbances is mesh implantation to replace the weakened pelvic fascia tissue so that necessary support is provided and autologous tissues could be grown in the presence of this scaffold [2]. As the mesh applied is usually weaved by single monofilament [3], the properties of PP monofilaments play a key role in the determination of the quality of meshes [4]. In spite of the fact that the mesh composed of PP monofilament has shown excellent performance in treatment of female pelvic floor surgery, some side-effects such as inflammation, infection and even serious complications are observed $[5,6]$. Therefore, it is necessary to improve the biocompatibility of the monofilaments. According to the characteristics of pelvic floor tissues repair, an ideal mesh shall present good biocompatibility, negative foreign body reaction, excellent elasticity and flexibility, easy stitching, with collagen fibers

\footnotetext{
* Address for correspondence: Guang Li, State Key Laboratory for Modification of Chemical Fibers and Polymer Materials, College of Material Science and Engineering, Donghua University, Shanghai, 201620, China. Tel.: +86-13501658697; Fax: +8667792830; E-mail: lig@dhu.edu.cn.
} 
grown on, capability of helping body tissue repair permanently, sufficient mechanical strength, highly anti-infection and less complication [7]. As a non-toxic non-irritating and bioactive material, pearl powder has been reported to be an ideal stimulator of osteoblast proliferation [8].

In this article, natural pearl powders were mixed with PP resin and the blend was spun into monofilaments. The effect of pearl powder on the biocompatibility of the PP monofilaments obtained was investigated.

\section{Experimental}

\section{1. Materials and samples preparation}

Medical polypropylene (MI=11.5 g/10min) was purchased from Sinopec Shanghai Petrochemical Company Limited and the pearl powders (diameter $=400 \pm 100 \mathrm{~nm}$ ) were commercially available. A kneader machine (Donghua University, China) was used for the blending of the pearl powder and PP resin at a temperature of $90^{\circ} \mathrm{C}$ and speed of $3600 \mathrm{r} / \mathrm{s}$ for $60 \mathrm{~min}$ to obtain blends containing $1 \mathrm{wt} \%$, $1.5 \mathrm{wt} \%$, and $2 \mathrm{wt} \%$ of pearl powders respectively.

The pristine and modified PP monofilaments were obtained by melt spinning of PP and pearl powder filled PP resin, respectively, with process parameters as follow: spinneret diameter was $3 \mathrm{~mm}$ with a length-diameter ratio of 4 , screw temperature ranged from $250^{\circ} \mathrm{C}$ to $260^{\circ} \mathrm{C}$, spinning pack temperature was $265^{\circ} \mathrm{C}$, spinning die temperature was $265^{\circ} \mathrm{C}$, cooling temperature of water bath was $25^{\circ} \mathrm{C}$, drawing temperature of water bath was $90^{\circ} \mathrm{C}$, heat setting temperature was $130^{\circ} \mathrm{C}$ and the draw ratio was 3.2.

\subsection{Analytical methods}

TGA was performed with a TG209 F1 instrument from Netzsch, Germany. The TGA scans were recorded at $10 \mathrm{~K} / \mathrm{min}$ under a nitrogen atmosphere from room temperature to $873 \mathrm{~K}$. The mechanical properties of the PP monofilaments obtained were measured using a fiber stretching tester (A0$3000 \mathrm{cN}$, Donghua University, China). The sound velocity values of various monofilaments presented in Table 1 were measured by sonic velocity testing meter (SCY-III, Donghua University, China). Then, the monofilaments were characterized by scanning electron microscopy to investigate the morphologies (Phenom G2 Pro, Phenom, China). Methyl thiazolyl tetrazolium (MTT) assay was carried out to evaluate the toxicity of PP monofilament. L929 fibroblasts of mice and porcine endothelial cell (PIEC) were cultivated in a medium containing 89\% Dulbecco's modified Eagle's medium (DMEM) with high glucose, $10 \%$ fetal bovine serum with none mycoplasma and $1 \%$ doubleantibody (penicillin and streptomycin) [9]. Enzyme-labeling measuring instrument was used (492 nm and $570 \mathrm{~nm}$ ) for measurement of the culture medium absorbance (expressed as optical density (OD)) on $1,4,7$ days and the relative proliferation rate was defined by the formula as follow $[10,11]$ :

$$
\text { the relative proliferation rate }(\%)=\frac{\text { OD value of experiment group }}{\text { OD value of negative controlgroup }} \times 100
$$




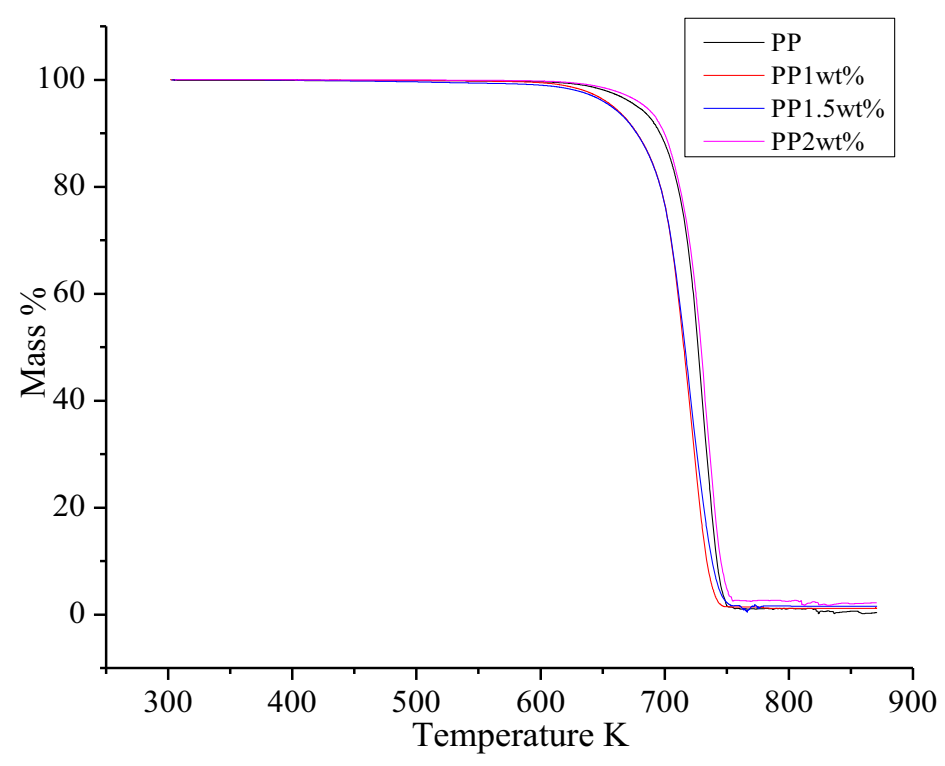

Fig. 1. TGA curves of pristine PP monofilaments and modified PP monofilaments with pearl powders.

In this study, the negative control group refers to pristine PP monofilaments. Finally, characterization by confocal microscopy was conducted to obtain the morphology of L929 so that the biocompatibility of modified PP monofilaments may be analyzed.

\section{Results and discussion}

\subsection{TGA of PP monofilaments}

In order to confirm the percent of pearl powders contents of the modified PP monofilaments, TGA was done both on pristine PP monofilaments and modified PP monofilaments with pearl powders. The TGA weight loss curves of the four samples are presented in Figure 1. The results showed that the residual amount of modified PP containing $2 \mathrm{wt} \%$ of pearl powders at $873 \mathrm{~K}$ was $2.18 \mathrm{wt} \%$, and the residual amounts of PP with $1.5 \mathrm{wt} \%$ and $1 \mathrm{wt} \%$ of pearl powders were $1.52 \mathrm{wt} \%, 1.14 \mathrm{wt} \%$ respectively. While the residual amount of pristine PP at $873 \mathrm{~K}$ was $0.38 \mathrm{wt} \%$. Therefore, it was proved that the contents of pearl powders of modified PP monofilaments were consistent with the expectation.

\subsection{Mechanical properties of PP monofilaments}

Table 1 shows the mechanical properties of four monofilaments with different contents of pearl powder. No significant variation was observed in strength when the pearl powder content is between $0 \% \sim 2 \%$ and the value of tensile strength was approximately $0.36 \mathrm{GPa}$, while the elongation at break decreased from $16.10 \%$ to $13.83 \%$ and the tensile modulus of monofilaments increased with the increasing content of pearl powder, the differences of elongation at break among the four groups had 
statistical significance. The pearl powder presents higher rigidity than PP matrix does, resulting in the change of mechanical properties. For the PP containing $2 \mathrm{wt} \%$ of pearl powders, there might be agglomerations of pearl powders, which could lead to a sudden increase in tensile modulus and decrease in elongation at break. In summary, the modified PP monofilaments showed good mechanical properties that satisfy the requirement of mesh weaving when content of pearl powders was below $2 \mathrm{wt} \%$. The sound velocity values of all the PP monofilaments listed in Table 1 may indicate the disturbing effect of pearl powder on the spread of sound along the monofilament. According to polymer physics, the presence of pearl powder, as a media adding into PP, can increase the sound velocity among molecules, resulting in a conduction delay in the macromolecule chains [12]. From another point of view, it serves as an indicator that pearl powders were well dispersed in the PP matrix.

\subsection{Morphologies of modified PP monofilaments}

It has been proved that the introduction of pearl powders may have an effect on the biocompatibility of PP monofilaments. According to the SEM images of different monofilaments shown in Figure 2, some white particles were observed on the surface of monofilaments and the number of these particles increased with increasing content of pearl powders. Indeed, these white particles are believed to be particles of pearl powder, indicating that pearl powder was distributed both on the surface and in the interior of monofilaments. As for the agglomeration, we can see its effect from Table 1: the elongation at break of PP monofilament decreases as pearl powders increase. And this is because the stress concentration points become larger when there are agglomerations.

\subsection{MTT assay for cell proliferation and cytotoxicity testing for PP monofilaments}

The mouse fibroblast cell line L929 and porcine endothelial cell (PIEC) cultured in vitro were used to evaluate the cytotoxicity of pearl powder filled PP monofilaments by MTT assay. MTT, a kind of bromine salt, can react with succinate dehydrogenase in living cells and yield insoluble purple precipitates in the cell. Indeed, the purple precipitates can be dissolved in dimethylsulfoxide (DMSO) and its concentration, which reflects the quantity of living cells, can be indicated by the absorption value, which is the optical density(OD) of certain wavelengths (492nm and 570nm, respectively) measured by enzyme-labeling measuring instrument (MULSIKAN MK3, Thermo, USA) [13, 14]. The results are shown in Figures 3 and 4.

Table 1

Mechanical properties of PP monofilaments

\begin{tabular}{lllll}
\hline Pearl powder content $(\mathrm{wt} \%)$ & 0 & 1 & 1.5 & 2 \\
\hline Tensile strength $(\mathrm{GPa})$ & $0.36 \pm 0.02$ & $0.36 \pm 0.03$ & $0.36 \pm 0.02$ & $0.36 \pm 0.02$ \\
Tensile modulus $(\mathrm{GPa})$ & $2.88 \pm 0.03$ & $2.98 \pm 0.03$ & $3.05 \pm 0.04$ & $3.30 \pm 0.05$ \\
Elongation at break $(\%)$ & $16.10 \pm 0.03$ & $15.22 \pm 0.02$ & $15.14 \pm 0.03$ & $13.83 \pm 0.03$ \\
Sound velocity $(\mathrm{km} / \mathrm{h})$ & $12.56 \pm 1.15$ & $12.42 \pm 1.06$ & $12.02 \pm 0.81$ & $11.81 \pm 1.09$ \\
\hline
\end{tabular}




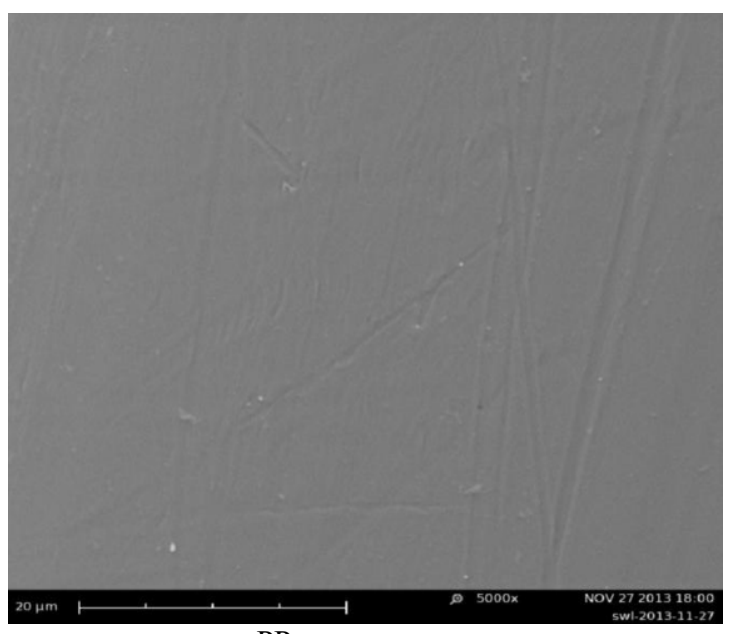

PP

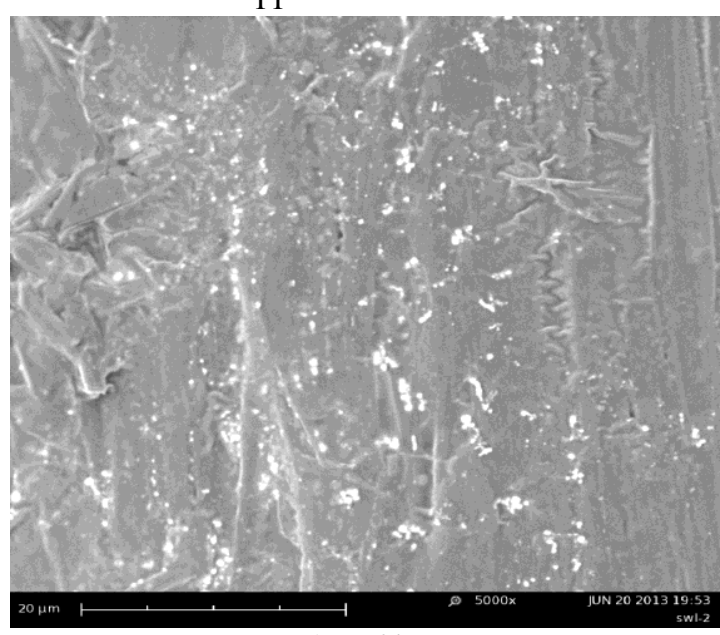

PP $1.5 \mathrm{wt} \%$

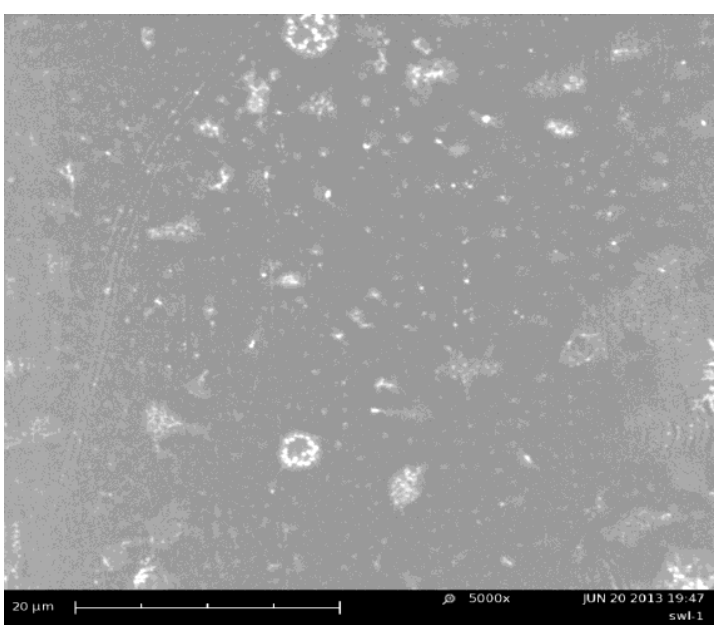

PP $1 \mathrm{wt} \%$

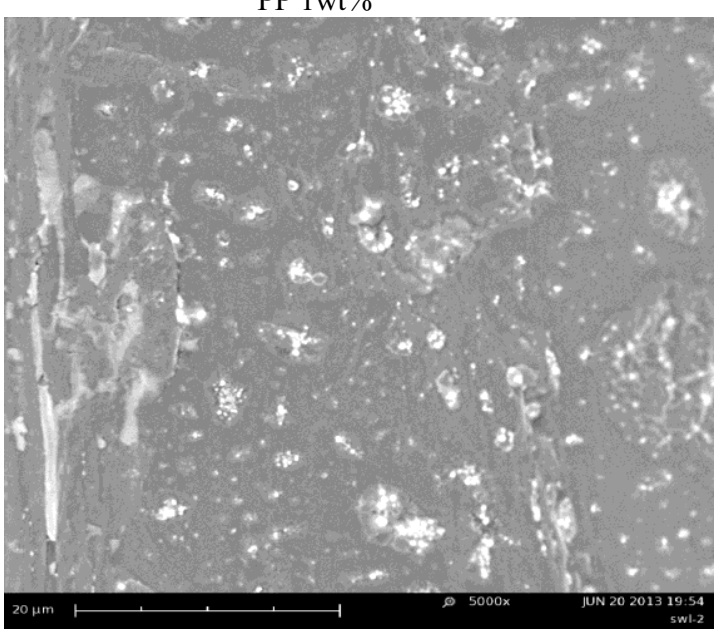

PP $2 w t \%$

Fig. 2. SEM images of PP monofilaments.

The MTT assay revealed that the cell proliferation of L929 and PIEC was accelerated during the incubation from 1 day to 7 days. Under the same conditions, the monofilaments containing pearl powders showed higher OD values than pristine PP did. The relative proliferation rates were calculated and shown in Tables 2 and 3. As is shown, the cell proliferation rate of monofilaments containing pearl powder was higher than that of monofilaments without pearl powder. In addition, the cell proliferation rate showed a positive correlation with the content of pearl powder. Therefore, it can be concluded that introduction of a small amount of pearl powder into the PP monofilaments can enhance the cell viability, promote the cell proliferation process and significantly improve the biocompatibility of PP monofilaments. 

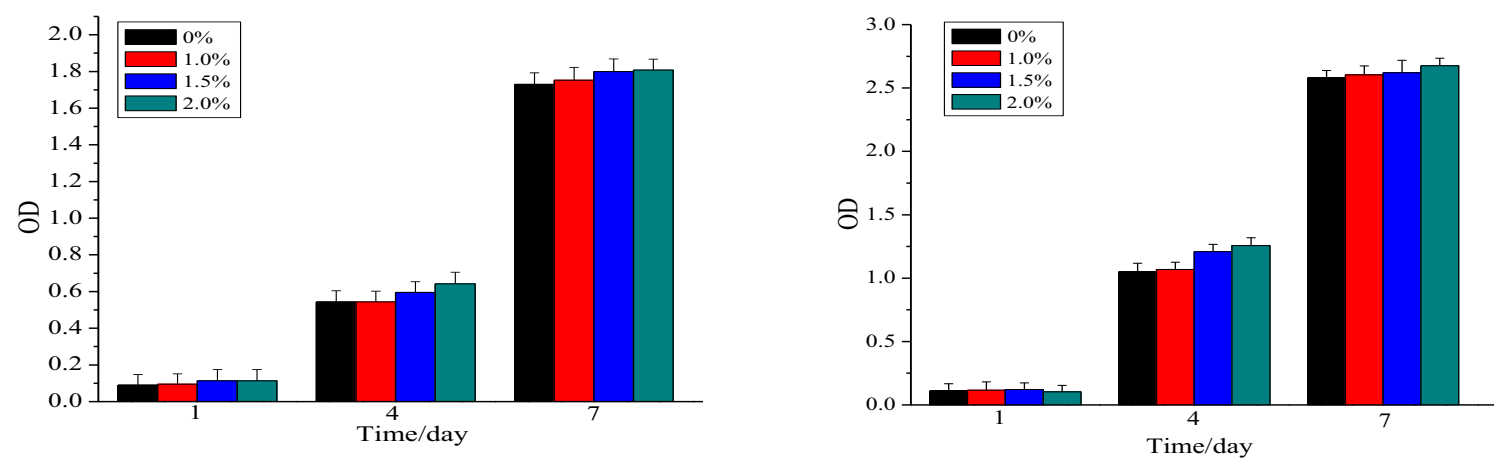

Fig. 3. Cytotoxicity for L929 cells left: $492 \mathrm{~nm}$ right: $570 \mathrm{~nm}$.
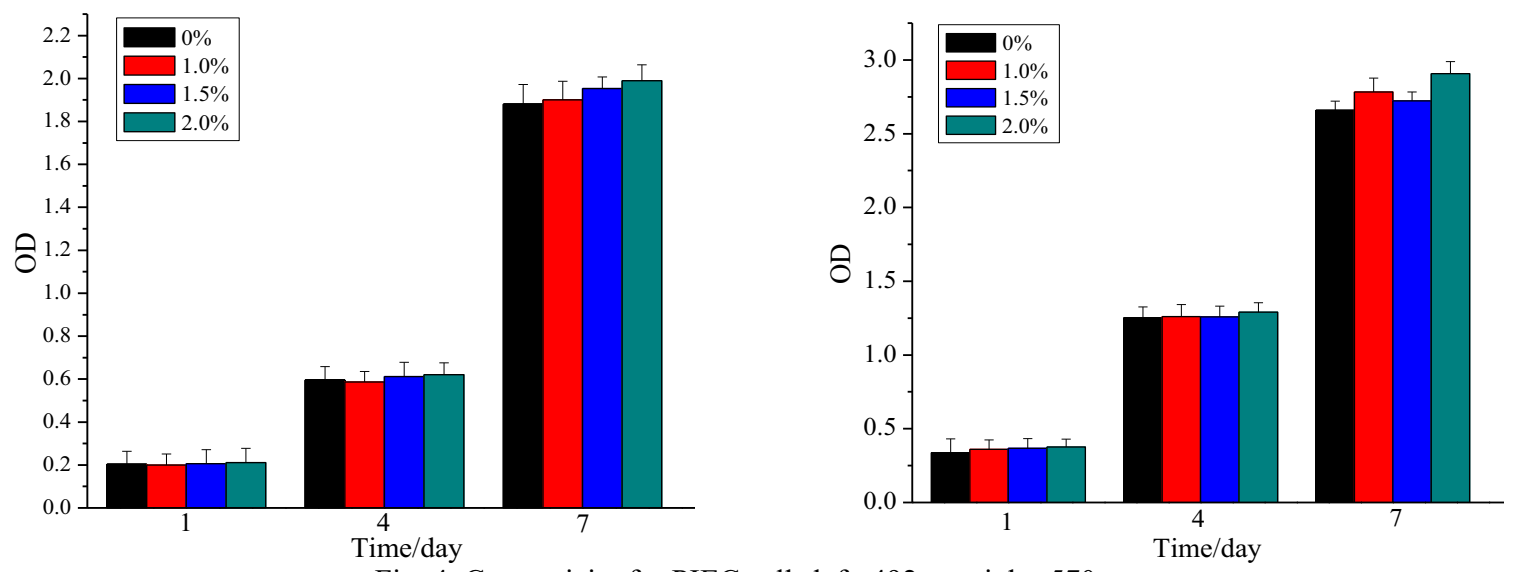

Fig. 4. Cytotoxicity for PIEC cells left: $492 \mathrm{~nm}$ right: $570 \mathrm{~nm}$

Table 2

L929 relative proliferation rates (\%) measured at $492 \mathrm{~nm}$ and $570 \mathrm{~nm}$

\begin{tabular}{lllllllll}
\hline & \multicolumn{3}{c}{ Time /day } & \multicolumn{3}{c}{ PP $1 \mathrm{wt} \%$} & PP 1.5wt\% & PP 2wt\% \\
\cline { 2 - 8 } & $492 \mathrm{~nm}$ & $570 \mathrm{~nm}$ & $492 \mathrm{~nm}$ & $570 \mathrm{~nm}$ & $492 \mathrm{~nm}$ & $570 \mathrm{~nm}$ & $492 \mathrm{~nm}$ & $570 \mathrm{~nm}$ \\
\hline 1 & 100 & 100 & 105 & 100 & 108 & 104 & 108 & 113 \\
4 & 100 & 100 & 101 & 102 & 110 & 114 & 118 & 119 \\
7 & 100 & 100 & 102 & 109 & 104 & 101 & 105 & 104 \\
\hline
\end{tabular}

Table 3

PIEC relative proliferation rates (\%) measured at $492 \mathrm{~nm}$ and $570 \mathrm{~nm}$

\begin{tabular}{lllllllll}
\hline \multirow{2}{*}{ Time /day } & PP & \multicolumn{3}{c}{ PP 1wt $\%$} & PP 1.5wt $\%$ & PP 2wt $\%$ \\
\cline { 2 - 8 } & $492 \mathrm{~nm}$ & $570 \mathrm{~nm}$ & $492 \mathrm{~nm}$ & $570 \mathrm{~nm}$ & $492 \mathrm{~nm}$ & $570 \mathrm{~nm}$ & $492 \mathrm{~nm}$ & $570 \mathrm{~nm}$ \\
\hline 1 & 100 & 100 & 101 & 103 & 107 & 107 & 109 & 109 \\
4 & 100 & 100 & 100 & 100 & 102 & 102 & 106 & 108 \\
7 & 100 & 100 & 101 & 102 & 103 & 103 & 104 & 104 \\
\hline
\end{tabular}




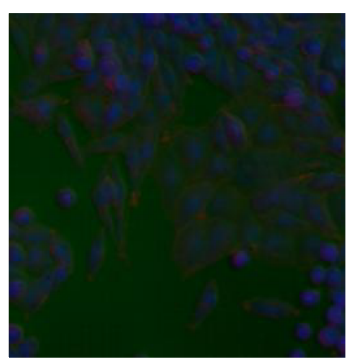

$\mathrm{pp}$

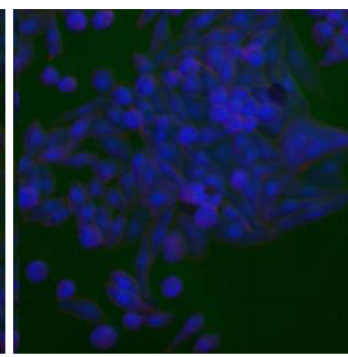

pp $1 \mathrm{wt} \%$

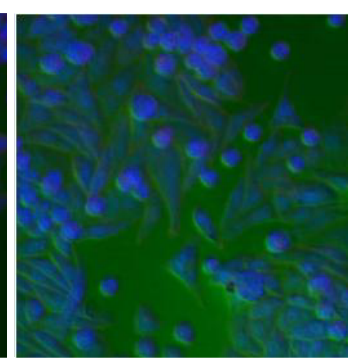

pp $1.5 \mathrm{wt} \%$

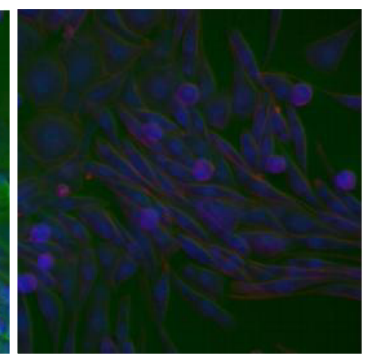

pp $2 \mathrm{wt} \%$

Fig. 5. Confocal microscopy images of L929 cells cultivated.

\subsection{Morphology of L929 cells}

The L929 cells cultivated were characterized by confocal microscopy and the results are shown in Figure 5. The cytomembrane and cytoplasm dyed with phalloidin appeared to be red after red fluorescence irradiation, while the cell nucleus dyed with DAPI appeared to be blue after blue fluorescence irradiation. Indeed, the cell nucleus and cytoplasm of L929 cells growing in the various extracted liquid of PP monofilaments with different pearl powder contents were significantly different from one another and most of the cells were spindle-shaped. The results showed that both the extracted liquid of pristine PP monofilament and that of pearl power filled PP filament had an effect on the cellular growth. In particular, in the case of the PP containing $2 \mathrm{wt} \%$ of pearl powders, the cells were attached to the bottom of the plate and the pseudopods stretched out. Therefore, it could be concluded that the presence of pearl powder in PP monofilaments had a positive effect on the cellular growth of L929. Additionally, the modified PP monofilaments containing pearl powder presented excellent biocompatibility with L929 cells.

\section{Conclusion}

The PP monofilaments prepared using the PP resin with $1 \sim 2 \mathrm{wt} \%$ of pearl powders showed similar mechanical properties with the pristine PP monofilament. The MTT assay revealed that the cell proliferation rate was higher in PP monofilaments containing pearl powders than in pristine PP monofilaments under the same culture conditions. Furthermore, the cell proliferation rate exhibited a positive correlation with the pearl powder content. In addition, characterization by confocal microscopy showed that the presence of pearl powders led to enhanced biocompatibility of the monofilaments. As a result, it is concluded that the introduction of pearl powder can improve the cell activity of PP monofilaments and promote the cells proliferation, which will in turn contribute to the biocompatibility of meshes made from PP monofilaments.

\section{References}

[1] K. Huang, F. Chuang and H. Fu, Polypropylene mesh as an alternative option for uterine preservation in pelvic reconstruction in patients with uterine prolapse, Journal of Obstetrics and Gynaecology Research 38.1 (2012), 97-101.

[2] K. Baessler and C.F. Maher, Mesh augmentation during pelvic-floor reconstructive survey: Risks and benefits, Current Opinion in Obstetrics and Gynecology 18.5 (2006), 560-566.

[3] S. Vimplis and P. Hooper, Assessment and management of pelvic organ prolapse, Current Obstetrics \& Gynaecology 15.6 (2005), 387-393. 
[4] C. Birch, The use of prostheties in pelvic reconstruction surgery, Best Practice \& Research in Clinical Obstetrics \& Gynaecology 19.6 (2005), 979-991.

[5] E. Matthew and S.V. Falagas, Mesh-related infections after pelvic organ prolapse repair surgery, European Journal of Obstetrics \& Gynecology and Reproductive Biology 134.2 (2007), 147-156.

[6] E. Mistrangelo, S. Mancuso and C. Nadalini, Rising use of synthetic mesh in transvaginal pelvic reconstructive surgery: a review of the risk of vaginal erosion, Journal of minimally invasive gynecology 14.5 (2007), 564-569.

[7] R.D. Tayrac, M. Oliva-Lauraire and I. Guiraud, Long-lasting bioresorbable poly (lactic acid)(PLA94) mesh: A new approach for soft tissue reinforcement based on an experimental pilot study, International Urogynecology Journal 18.9 (2007) 1007-1014.

[8] Y. Shen, J. Zhu and H. Zhang, In vitro osteogenetic activity of pearl, Biomaterials 27.2 (2006), 281-287.

[9] J. Sun, Z. Dai and Y. Zhao, In vitro effect of oligo-hydroxyalkanoates on the growth of mouse fibroblast cell line L929, Biomaterials 28.27 (2007), 3896-3903.

[10] S. Grekova, R. Zawatzky and R. Horlein, Activation of an antiviral response in normal but not transformed mouse cells: A new determinant of minute virus of mice oncotropism, Journal of virology 84.1 (2010), 516-531.

[11] D. Guo, K. Xu and X. Zhao, Development of a strontium-containing hydroxyapatite bone cement, Biomaterials 26.19 (2005), 4073-4083.

[12] B.R. Liang, Orientation structure, in: Polymer physics, B.R.Liang, ed., China Textile Press, Shanghai, 2000, pp. 75-81

[13] L. Peng, B. Wang and P. Ren, Reduction of MTT by flavonoids in the absence of cells, Colloids and Surfaces B: Biointerfaces 15.2 (2005), 108-111.

[14] A.M. Schrand, H. Huang and C. Carlson, Are diamond nanoparticles cytotoxic? The Journal of Physical Chemistry B 111.1 (2007) 2-7. 